\title{
Dentin regeneration by stem cells of apical papilla on injectable nanofibrous microspheres and stimulated by controlled BMP-2 release
}

\author{
Wei Wang ${ }^{\text {a,b }}$, Ming Dang ${ }^{\mathrm{c}}$, Zhanpeng Zhang ${ }^{\mathrm{d}}$, Jiang Hü ${ }^{\mathrm{a}}$, Thomas W Eyster ${ }^{\mathrm{a}}$, Longxing Ni b,\#, \\ Peter X Ma ${ }^{\text {a,c,d,e,* }}$ \\ ${ }^{\text {a }}$ Department of Biologic and Materials Sciences, University of Michigan, Ann Arbor, MI 48109, USA \\ ${ }^{\mathrm{b}}$ State Key Laboratory of Military Stomatology, Department of Operative Dentistry and Endodontics, School of \\ Stomatology, The Fourth Military Medical University, Xi’an 710032, People’s Republic of China \\ ${ }^{\mathrm{c}}$ Macromolecular Science and Engineering Center, University of Michigan, Ann Arbor, MI 48109, USA \\ ${ }^{\mathrm{d}}$ Department of Biomedical Engineering, University of Michigan, Ann Arbor, MI 48109, USA \\ ${ }^{\mathrm{e}}$ Department of Materials Science and Engineering, University of Michigan, Ann Arbor, MI 48109, USA
}

* Corresponding Author:

Peter X. Ma, PhD, Professor

Department of Biologic and Materials Sciences

1011 North University Ave., Room 2211

University of Michigan, Ann Arbor, MI 48109-1078, USA.

Tel.: +1 734764 2209; Fax: +1 734647 2110; E-mail address: mapx@umich.edu.

\#Corresponding Author: Tel/Fax: +86 29 84776476; E-mail address: Longxing_Ni@hotmail.com. 


\begin{abstract}
The aim of this study was to investigate the effects of PLLA nanofibrous microspheres (NF-MS) as a cell delivery carrier in combination with controlled release of BMP-2 from PLGA microspheres on the induction of odontogenic differentiation of human stem cells of apical papilla (SCAP). Injectable NF-MS, which mimic the physical architecture of collagen fibers on the nano scale, were fabricated by combining thermally-induced phase separation techniques with an emulsification process. SCAP cultured in a monolayer or cultured on NF-MS in spinner flasks were treated with $100 \mathrm{ng} / \mathrm{ml} \mathrm{BMP-2}$ in vitro. Odontogenic differentiation was characterized by measuring alkaline phosphatase activity, odontogenic gene expression levels, calcium content, and dentin sialophosphoprotein accumulation. The results demonstrated that BMP-2 enhanced human SCAP odontogenic differentiation both in monolayer culture and on 3D NF-MS in spinner flask culture in vitro. We also developed and tested a system combining NF-MS with controlled BMP-2 release for dentin regeneration in vivo. The results indicate that controlled release of BMP-2 promoted more mineralization and osteodentin formation compared to a BSA-releasing control in a dose-dependent and time-dependent manner. In summary, the NF-MS combined with controlled release of BMP-2 provides an excellent microenvironment for SCAP to regenerate dentin tissue.
\end{abstract}

\title{
Keywords
}

Stem cells of apical papilla (SCAP), Nanofibrous microspheres (NF-MS),

Odontogenic differentiation, Bone morphogenetic protein-2 (BMP-2), Controlled delivery 


\section{Introduction}

Tooth lesion and loss caused by dental caries, periodontal diseases and trauma are prevalent diseases, which may affect masticatory efficiency, speaking function, facial aesthetics and even psychological health [1]. Current treatment methods depend on inert restorative materials, such as amalgam, resins and glass ionomers, few of which resemble the physical or chemical characteristics of natural tooth. This may explain why a high proportion of cavity restorations fail mechanically [2]. Tissue engineering may have the potential to regenerate the natural structure of teeth as a better alternative to existing treatment regimens for tooth lesion and loss. Realizing the potential of regenerative treatments for teeth requires the integration of an extracellular matrix-mimicking scaffold, appropriate progenitor/stem cells and morphogens [3].

Tissue engineering approaches often benefit from advanced scaffolds that provide a physicochemical and biological three-dimensional microenvironment for cell attachment, proliferation, differentiation and neo-tissue genesis. Biodegradable polymer microspheres as tissue engineering scaffolds have received increasing attention for their potential to regenerate and repair irregularly-shaped tissue defects due to their injectability, controllable biodegradability, and capacity of drug incorporation and release, making possible a clinical protocol that features minimal invasion and short-term manipulation in comparison to traditional surgical procedures [4, 5]. Biodegradable microspheres can be advantageous in repairing small irregularly-shaped dentin defects and allows for easier treatment of traditionally hard-to-reach dental defects. Recently, injectable nanofibrous microspheres (NF-MS) have been developed and fabricated in our lab [6]. The nanofibers of the NF-MS mimic the physical architecture of collagen with an average diameter of about $160 \mathrm{~nm}$, facilitating cell adhesion, proliferation and differentiation [6,7]. NF-MS have a much higher porosity and surface area when compared to traditional solid interior microspheres (SI-MS). These characteristics have been shown to facilitate cell growth, nutrient/waste 
exchange and faster scaffold degradation $[6,8]$. We would like to evaluate the novel NF-MS for dentin regeneration in this study. Among different types of human dental stem/progenitor cells, stem cells of apical papilla (SCAP) are of particular interest in regenerative endodontics because of their anatomical position at the site of the root development process [9] and their superiority in forming more uniform dentin-like tissue [10], much higher proliferation rate, mineralization rate and dentin regeneration capacity over dental pulp stem cells (DPSCs). Moreover, SCAP, derived from a developing tissue (apical papilla), may represent a population of early stem/progenitor cells, being potentially a superior cell source for tissue regeneration [11].

As an important morphogenic factor, bone morphogenetic protein 2 (BMP-2) has been shown to be odontogenic and osteogenic both in vitro and in vivo [12-17]. BMP-2 has many functions: it stimulates differentiation of bovine, porcine, canine and human DPSCs into odontoblasts (resulting in dentin formation) $[13,14,18]$, induces dental follicle progenitor cells (DFPCs) to differentiate towards a cementoblast/osteoblast phenotype [19], and can also induce odontogenesis of stem cells from human exfoliated deciduous teeth (SHED) and human tooth germ stem cells $[20,21]$. However, the role of BMP-2 in regulating human SCAP odontogenesis remains largely unknown. It is important to evaluate the response of human SCAP to BMP-2 for potential tooth tissue regeneration. Notably, a short half-life, large dose requirement, high cost and the need for repeated administration limit direct injection of soluble BMP-2 into a defect site [22]. Consequently, a controlled delivery system for BMP-2 becomes increasingly desired for sustaining efficacious levels of BMP-2 in vivo [23]. This far, various types of biomaterial carriers for BMPs have been developed, such as poly(lactic-co-glycolic acid) (PLGA), collagen, hydrogels, and calcium phosphates, as well as these combinations [24]. Among them, PLGA has been well characterized as a biocompatible carrier for controlled delivery of polypeptides and proteins in the format of microspheres or nanospheres [25]. Our previous work demonstrated that incorporating PLGA microspheres (PLGA MS) loaded with platelet-derived 
growth factor (PDGF) or bone morphogenetic protein 7 (BMP-7) onto nanofibrous poly(L-lactic acid) (NF-PLLA) scaffolds successfully promoted osteogenesis or soft tissue neogenesis, respectively [26, 27]. However, the inducible effect of controlled-releasing BMP-2 encapsulated in PLGA MS on dentin regeneration has not been studied using a microsphere system.

The purpose of this study was to evaluate the utility of PLLA NF-MS as a cell delivery carrier, in combination with PLGA microspheres for controlled BMP-2 release, for induction of odontogenic differentiation of human SCAP. We hypothesize that injectable NF-MS and controlled release of BMP-2 synergistically induce the odontogenesis of human SCAP. To test this hypothesis, the odontogenic differentiation of human SCAP in a monolayer culture and on 3D NF-MS in a spinner flask culture was first evaluated with BMP-2 treatment. Then, the combination of PLLA NF-MS with PLGA microspheres for BMP-2 release was used for 3D SCAP culture (against control PLLA SI-MS). The mixture was subcutaneously injected into mice to study odontogenic differentiation of human SCAP in vivo.

\section{Materials and methods}

\subsection{Materials}

Poly(L-lactic acid) (PLLA) (RESOMER® L207 S) and poly(lactic-co-glycolic acid) (PLGA) copolymer with LA/GA ratio of 50:50 (PLGA50-64K, Mw=64 kDa) were purchased from Evonik Industries (Birmingham, AL). Glycerol was purchased from Sigma-Aldrich Inc (St. Louis, MO) and used without further purification. Deionized water was obtained with a Milli-Q water filter system from Millipore Corporation (Bedford, MA). Other chemicals used were: poly(vinyl alcohol) (PVA) (87-89\% hydrolyzed, Mw=89,000-98,000), trifluoroacetic acid (TFA), bovine serum albumin (BSA) and gelatin (type B from bovine skin), dichloromethane, cyclohexane, hexane and 
tetrahydrofuran (THF) from Sigma-Aldrich Inc. Recombinant human bone morphogenetic protein 2 (BMP-2) was kindly provided by Medtronic Inc. (Minneapolis, MN)

\subsection{Preparation of PLLA NF-MS and BMP-2 releasing PLGA MS}

PLLA was dissolved in tetrahydrofuran at $50^{\circ} \mathrm{C}$ with a concentration of $2.0 \%(\mathrm{wt} / \mathrm{v})$. Under rigorous mechanical stirring (speed 7, MAXIMA, Fisher Scientific), glycerol $\left(50^{\circ} \mathrm{C}\right)$ with three times the volume of PLLA solution was gradually added into the PLLA solution, and the stirring continued for 5 min afterwards. The PLLA and glycerol mixture was then quickly poured into liquid nitrogen. After $10 \mathrm{~min}, 1,000 \mathrm{ml}$ water-ice mixture was added for solvent exchange for $24 \mathrm{~h}$. The NF-MS were sieved and washed with an excessive amount of distilled water six times to remove glycerol residue, and then lyophilized for 3 days.

BMP-2 PLGA MS were prepared using double emulsion method established previously [26]. BMP-2 (10 $\mu \mathrm{g} / \mathrm{mg}$ polymer) was encapsulated into PLGA50-64K MS, and gelatin/BSA encapsulated into PLGA50-64K MS was prepared as controls. Briefly, BMP-2 solution was prepared by dissolving lyophilized BMP-2 powder in 0.1\% TFA solution with $0.1 \mathrm{wt} \%$ gelatin and BSA. PLGA 50/50 with $\mathrm{Mw}$ of $64 \mathrm{kDa}$ was used, targeting the release rate that had been shown to be advantageous in our previous study on rhBMP-7 release [26]. The BMP-2 solution was emulsified in a 5\% w/v PLGA polymer solution in dichloromethane (DCM), using a probe sonicator at an output power of $10 \mathrm{~W}$ (Virsonic 100, Cardiner, NY) for $10 \mathrm{~s}$ over an ice bath to form a water-in-oil (w/o) emulsion. The w/o emulsion was then gradually added into $20 \mathrm{ml}$ aqueous PVA solution $(1 \% \mathrm{w} / \mathrm{v})$ under sonication at an output power of $20 \mathrm{~W}$ to form a water-in-oil-in-water (w/o/w) double emulsion. The solution was stirred at room temperature for $3 \mathrm{~h}$ to evaporate dichloromethane and then centrifuged to collect microspheres. The resulting microspheres were washed with distilled water three times and freeze-dried.

\subsection{Cell culture}


Normal impacted third molars at the stage of root development (5 patients with age between 16-18 years, male or female) were extracted from patients at the University of Michigan School of Dentistry following a protocol approved by the Institutional Review Board at the University of Michigan. Human SCAP were isolated following a published procedure [28]. Briefly, apical papilla were removed from teeth, minced, and digested in a solution of 3 $\mathrm{mg} / \mathrm{ml}$ of collagenase type I and $4 \mathrm{mg} / \mathrm{ml}$ dispase for $30-60 \mathrm{~min}$ at $37^{\circ} \mathrm{C}$. The digested mixture was passed through a $70 \mathrm{~mm}$ cell strainer (Falcon; BD Lab-ware, Franklin Lakes, NJ) to obtain a single-cell suspension. Cells were seeded onto six-well plates and cultured in alpha modification of Eagle's medium ( $\alpha$-MEM) (Invitrogen, Carlsbad, CA) supplemented with 15\% fetal bovine serum (FBS) (Invitrogen), 1\% Penicillin-Streptomycin (Invitrogen), 0.1 $\mathrm{mM}$ L-ascorbic acid 2-phosphate (WAKO, Tokyo) and $2 \mathrm{mM} \mathrm{L-glutamine} \mathrm{(Invitrogen)} \mathrm{and} \mathrm{then} \mathrm{maintained} \mathrm{at} 37^{\circ} \mathrm{C}$ in a humidified atmosphere containing 5\% $\mathrm{CO}_{2}$. Single-cell-derived colony cultures were obtained using the limiting dilution technique. After reaching $80 \%-90 \%$ confluence, cells were collected and passaged at 1:3 for further experiments. Multiple colony-derived SCAPs at passage numbers from 3-6 were used for all the experiments presented in this article. Multipotent differentiation and surface molecular characterization of SCAP were carried out as previously described [29] (see Supplementary Methods).

\subsection{Proliferation of human SCAP in monolayer culture}

An MTS (3-(4,5-dimethylthiazol-2-yl)-5-(3-carboxymethoxyphenyl)-2-(4-sulfophenyl)-2H-tetrazolium, inner salt) assay was performed to investigate cell proliferation using CellTiter 96 AQueous One Solution (Promega, Madison, WI). Briefly, SCAP were seeded into 96 -well plates at a density of $2 \times 10^{3}$ cells per well, and treated with BMP-2 (100 ng/ml) for 7 days. At days 1, 3, 5 and 7, $20 \mu$ fresh MTS solution and $100 \mu$ l $\alpha$-MEM without FBS was added into each well and incubated for $2 \mathrm{~h}$ at $37^{\circ} \mathrm{C}$. The absorbance was measured at $490 \mathrm{~nm}$. SCAP that were not treated with BMP-2 were processed in an identical fashion to the experimental samples and served as controls. 
2.5. Alkaline phosphatase (ALP) assay and alizarin red staining of human SCAP in monolayer culture

Human SCAP were cultured in the $\alpha$-MEM containing $100 \mathrm{ng} / \mathrm{ml} \mathrm{BMP-2,} 50 \mu \mathrm{g} / \mathrm{ml}$ ascorbic acid and $10 \mathrm{mM}$

$\beta$-glycerophosphate. At days 3, 7 and 14, ALP activity of SCAP was assayed as described previously [30] with a SensoLyte ${ }^{\mathrm{TM}}$ pNPP Alkaline Phosphatase Assay Kit (AnaSpec, San Jose, CA) according to the manufacturer's protocol and normalized against total proteins. At weeks 2 and 4, alizarin red staining was carried out and images were acquired using a scanner. Image-Pro Plus 5.0 software was used to analyze total nodule areas. SCAP that were cultured in the $\alpha$-MEM containing $50 \mu \mathrm{g} / \mathrm{ml}$ ascorbic acid and $10 \mathrm{mM} \beta$-glycerophosphate were processed in an identical fashion to the experimental samples and served as controls.

\subsection{Cell seeding on NF-MS}

The NF-MS were pre-wetted in 70\% ethanol (v/v) for $30 \mathrm{~min}$, washed three times with phosphate buffered saline (PBS) (Invitrogen) for $30 \mathrm{~min}$ each, and washed once in cell culture medium for $30 \mathrm{~min} .3 \times 10^{6}$ cells and $1.5 \times 10^{5}$ NF-MS (20:1 ratio) were mixed together in $2 \mathrm{ml}$ of culture medium. The 2-ml cells/NF-MS suspension in a 15-ml tube was incubated at $37^{\circ} \mathrm{C}$ on an orbital shaker (Lab-Line, USA) at $12 \mathrm{rpm}$ in an incubator for 5 hours to allow for cell attachment and prevent the adherence of cells and microspheres onto the tube wall. After being gently shaken for 4-6 h, the cells/NF-MS mixture was transferred to a spinner flask (Wheaton, Millville, NJ) for long-term culture in $85 \mathrm{ml}$ odontogenic medium (containing $100 \mathrm{ng} / \mathrm{ml}$ BMP-2, $50 \mu \mathrm{g} / \mathrm{ml}$ ascorbic acid and $10 \mathrm{mM}$ $\beta$-glycerophosphate) or $85 \mathrm{ml}$ control medium (containing $50 \mu \mathrm{g} / \mathrm{ml}$ ascorbic acid and $10 \mathrm{mM} \beta$-glycerophosphate). The stirring rate was controlled at 75-80 rpm to keep the microspheres suspended in the medium. The medium was changed every three days. The suspension in the flask was precipitated 30-60 min after the stirring was stopped. The supernatant was then removed and replaced with fresh medium. Cells/NF-MS mixture was collected at different time points in order to measure ALP activity, calcium content, and expression of odontogenic genes and 
DSPP protein over time.

\subsection{ALP assay of SCAP cultured on NF-MS}

The ALP assay was performed in the same fashion as method 2.4 with the exception that the cell/microspheres mixture was homogenized prior to use here.

\subsection{Calcium content quantification}

For human SCAP cultured on NF-MS in vitro, the cells/NF-MS mixture was washed three times for 5 min each in distilled water and then homogenized in $300 \mu \mathrm{l}$ distilled water and $300 \mu \mathrm{l} 1 \mathrm{M}$ hydrochloric acid. For ectopic regeneration experiment, after weighing, the specimens were washed three times with distilled water and homogenized in $500 \mu \mathrm{l}$ distilled water and $500 \mu \mathrm{l} 1 \mathrm{M}$ hydrochloric acid. The lysate was incubated overnight at $4{ }^{\circ} \mathrm{C}$ to extract calcium. The total calcium content was determined by o-cresolphthalein-complexone method following the manufacturer's instructions (Calcium LiquiColor, Stanbio Laboratory, Boerne, TX). For ectopic specimens, the calcium content was normalized by per mg specimen.

\subsection{Real-time reverse transcriptase PCR (Real-time RT-PCR)}

Real-time RT-PCR was performed in an ABI ViiA7 Real-time PCR system (Applied Biosystems, Foster, CA) with TaqMan or SYBR Green PCR master mix (Life Technologies, Grand Island, NY). Total RNA was extracted using Trizol (Invitrogen) following manufacturer's protocol and cDNA was synthesized using SuperScript ${ }^{\circledR}$ II Reverse Transcriptase (Invitrogen). The four ready-made TaqMan primers were Hs00173720_m1 for bone sialoprotein (BSP), Hs01587814_g1 for osteocalcin (OCN), Hs00164004_m1 for collagen type I (Col I) and Hs99999905_m1 for glyceraldehyde-3-phosphate dehydrogenase (GAPDH). Two specificly designed primers were dentin sialophosphoprotein (DSPP) (sense 5'-TTAAATGCCAGTGGAACCAT-3'; $\quad$ antisense 
5'-ATTCCCTTCTCCCTTGTGAC-3') and GAPDH (sense 5'-GAGTCAACGGATTTGGTCGT--3'; antisense 5'-GACAAGCTTCCCGTTCTGAG -3'). RNA expression was normalized to GAPDH expression. All reactions were run in triplicate.

\subsection{Ectopic odontogenic differentiation of subcutaneous injection}

All animal surgery procedures conducted in the present study were approved by the University Committee on Use and Care of Animals (UCUCA) at the University of Michigan. Nude mice (6-8 weeks old, NU/NU, Charles River Laboratories, Wilmington, MA) were anaesthetized with $2 \%$ isoflurane in balanced oxygen. The cells/NF-MS mixture was cultured in odontogenic medium or control medium for 7 days prior to injection. The mixture was then centrifuged and resuspended in medium. The cells/NF-MS mixture was injected into subcutaneous pockets of nude mice on both sides lateral to the dorsal midline using a 25 -gauge needle. Each mouse received four injections, with each injection containing $3 \times 10^{6}$ cells and $1.5 \times 10^{5} \mathrm{NF}-\mathrm{MS}$. The injections were performed randomly into the two groups of nude mice $(n=6)$. The regenerated tissues were retrieved after 8 weeks and processed for histological and immunohistochemical examinations.

For controlled release of BMP-2, the subcutaneous injections were randomly performed in eight groups of nude mice ( $n=6)$. Each injection site contained $3 \times 10^{6}$ cells and $1.5 \times 10^{5}$ NF-MS. The procedure of injection was the same as for those without BMP-2 release described above. The four groups and two time points are: (1) NF-MS mixed with BSA PLGA MS (5 $\mu$ g per site) for 4 weeks and 8 weeks; (2) NF-MS mixed with BMP-2 PLGA MS (5 $\mu$ g per site) for 4 weeks and 8 weeks; (3) NF-MS mixed with BSA PLGAMS (25 $\mu$ g per site) for 4 weeks and 8 weeks; (4) NF-MS mixed with BMP-2 PLGA MS (25 $\mu$ g per site) for 4 weeks and 8 weeks. The BSA PLGA MS groups were used as controls. The regenerated tissues were retrieved after 4 and 8 weeks and processed for calcium content, real-time RT-PCR, and histological and immunohistochemical examinations. 


\subsection{Histology and immunohistochemistry}

For the in vitro studies, the cells/NF-MS mixture was cultured in odontogenic medium or control medium for 2 and 4 weeks and fixed in 4\% paraformaldehyde. Fixed mixture was treated with 0.1\% Triton X-100 (Sigma-Aldrich) for 5 min, blocked with 2\% BSA for 30 min (Sigma-Aldrich), and further incubated with DSPP mouse monoclonal IgG (1:50, Santa Cruz Biotechnology Inc, Santa Cruz, CA) overnight at $4^{\circ} \mathrm{C}$. Secondary antibody of FITC-conjugated goat anti-mouse IgG (1:70, Santa Cruz Biotechnology Inc) was applied for 60 min. To further observe cytoskeleton on the microspheres, Alexa Fluor 555 phalloidin (1:30, Life technologies) was applied for 30 min. Specimens were then mounted with Vectashield mounting medium containing DAPI (Vector Laboratories, Inc., Burlingame, CA) and observed under a confocal scanning laser microscope (CLSM, Nikon TS-100, Tokyo, Japan).

The ectopic specimens with BMP-2 $(100 \mathrm{ng} / \mathrm{ml})$ pretreatment were fixed directly in $10 \%$ formalin for $24 \mathrm{~h}$. The ectopic specimens with controlled BMP-2 release were fixed in 10\% formalin for $24 \mathrm{~h}$ and then decalcified in $10 \%$ EDTA (PH 7.4) for 1 week. All the specimens were then dehydrated, embedded in paraffin and sectioned into $7-\mu \mathrm{m}$ thick slices. The ectopic specimens with BMP-2 pretreatment were then stained with hematoxylin and eosin (H\&E), Von Kossa and DSPP antibody. The ectopic specimens with BMP-2 controlled release were stained with H\&E, Masson's Trichrome method, and DSPP antibody. For immunohistochemical staining, the sections were incubated with pepsin (Thermo Fisher Scientific, Wayne, MI) at $37{ }^{\circ} \mathrm{C}$ for $30 \mathrm{~min}$. After digestion, the sections were washed in PBS for three times and 5 min each, followed by peroxidase, serum, avidin and biotin blocking for 15 min each. Primary antibody against DSPP (1:50, Santa Cruz Biotechnology Inc.) was applied to sections at $4{ }^{\circ} \mathrm{C}$ overnight. Anti-Mouse HRP-AEC cell \& tissue staining kit (R\&D systems Inc, Minneapolis, MN) including a biotinylated secondary antibody was subsequently applied to the sections according to the protocol. The sections were then counterstained with hematoxylin and mounted. 


\subsection{Statistical analysis}

All data were presented as means \pm SD. For analysis of two unpaired groups, Student's t-test was applied. For analysis of multiple groups, one-way ANOVA followed by Tukey post-test was applied. Statistical analyses were performed with SPSS 18.0 software at a significance level of $P<0.05$.

\section{Results}

3.1 Multiple lineage differentiation and surface molecule characterization of SCAP.

The majority of the isolated SCAPs retained their fibroblast-like spindle shape similar to those observed for various mesenchymal stem cell populations (Fig. S1A). After 4 weeks of odonto/osteogenic or adipogenic induction, small round Alizarin red-positive nodules (Fig. S1B) or lipid droplets (Fig. S1C) formed in the SCAP cultures, indicating their capability of multiple lineage differentiation. Moreover, SCAP exhibited a characteristic pattern of mesenchymal surface markers STRO-1 and CD146 and a specific marker CD24 via flow cytometric analysis (Fig. S1D).

3.2. In vitro proliferation and odontogenic differentiation of human SCAP in monolayer culture

MTS assay revealed that the proliferation of BMP-2 treated SCAP was slightly slower than that of the control group at day 7 (Fig. 1A), but there were no significant differences between BMP-2 treated groups and control groups at days 1,3 and 5 .

To evaluate the effect of BMP-2 treatment on odontogenic differentiation of SCAP, ALP activity and matrix mineralization extent were measured at defined time points. ALP activity increased in both BMP-2 treated groups and control groups during 14 days of culture (Fig. 1B). ALP activity in BMP-2 treated groups was significantly higher than control groups at days 3, 7 and $14(p<0.05)$. Moreover, SCAP treated with BMP-2 developed a 
significantly higher number of mineralization nodules than control groups, as measured by alizarin red staining at weeks 2 and 4 (Fig. 1C). The quantification of mineralization nodule areas further confirmed this outcome (Fig. 1D).

3.3. In vitro odontogenic differentiation and mineralization of human SCAP cultured on NF-MS with BMP-2 treatment.

Having established that BMP-2 enhanced SCAP odontogenic differentiation in monolayer culture, a 3D culture system was next tested by growing BMP-2 treated SCAP on NF-MS in spinner flasks. Fig. 2A is a diagram illustrating the 3D spinner flask culture system. ALP activity increased in both BMP-2 treated groups and control groups during 14 days of culture. ALP activity was significantly higher in BMP-2 treated groups than control groups at days 7 and 14 ( $p<0.05)$, while no statistical difference was found at day 3 (Fig. 2B). Calcium content quantification demonstrated a greater amount of calcium deposition in BMP-2 treated groups than control groups at week 4 with statistically significant difference ( $p<0.05$, Fig. 2C).

The expression levels of genes related to the odontogenic differentiation were measured with real-time RT-PCR at weeks 2 and 4 (Fig.2D). The expression levels of Col I, BSP, OCN and DSPP genes were up-regulated with culture time in both BMP-2 treated groups and control groups. The expression levels of BSP, OCN and DSPP genes in BMP-2 groups were significantly higher than control groups at weeks 2 and $4(p<0.05)$, whereas the difference in expression level of Col I gene between the two groups was only significant at week $2(p<0.05)$.

DSPP protein was stained via immunofluorescence and imaged under confocal microscope (Fig. 3). DSPP protein expression in the control group was negligible at week 2, whereas significant DSPP protein expression was detected in the BMP-2 treated group at week 2. Consistently, there was a higher expression level of DSPP protein in the BMP-2 treated group than in the control group at week 4 . 
3.4. The ectopic odontogenic differentiation of human SCAP cultured on NF-MS with BMP-2 pretreatment.

Since BMP-2's efficacy in inducing odontogenesis in vitro has been thoroughly demonstrated, the effect of BMP-2 pretreatment on odontogenic differentiation of SCAP cultured on NF-MS were subcutaneously implanted for in vivo assessment. The regenerated tissues were retrieved and examined after 8 weeks of subcutaneous implantation in mice. Generally, all specimens were surrounded by thin fibrous connective tissues. The H\&E staining showed that more newly synthesized matrix and dentin-like tissues were present in BMP-2 treated groups (Fig. 4), whereas no dentin-like tissues were observed in control groups. Moreover, Von Kossa staining revealed more mineralized tissues in BMP-2 treated groups, while poorly mineralized tissues were observed in control groups (Fig. 4). Furthermore, DSPP expression was examined through immunohistochemical staining. The regenerated tissues in BMP-2 treated group showed strong staining for DSPP, especially in the surroundings of NF-MS, whereas regenerated tissues in control groups were only weakly stained for DSPP (Fig. 4).

3.5. The ectopic odontogenic differentiation of human SCAP cultured on NF-MS in combination with controlled release of BMP-2

After the pre-treatment of BMP-2 was assessed in the previous section, the effect of controlled release of BMP-2 using PLGA microspheres on odontogenic differentiation of SCAP cultured on NF-MS in vivo was assessed for potential application in the dental clinic. Fig. 5A illustrates subcutaneous implantation of the BMP-2 encapsulated microspheres (BMP2 MS)/NF-MS/SCAP mixture.

After 4 and 8 weeks of subcutaneous implantation, the specimens were retrieved and imaged with radiography (Fig. 5B). Specimens from BMP-2 release groups were encapsulated by thin red-colored (vascularized) fibrous connective tissues, while specimens in control BSA release groups were encapsulated by thin white-colored fibrous connective tissues (macroscopic observation, Fig. S2). The mineralization in $5 \mu \mathrm{g}$ and $25 \mu \mathrm{g}$ BMP-2 release groups 
at week 4 was not obvious and only present in the margins of the specimens, while the mineralization in corresponding BSA release groups was minimal. The mineralization in $5 \mu \mathrm{g}$ and $25 \mu \mathrm{g}$ BMP-2 release groups at week 8 was obvious, whereas no evident mineralization was observed in corresponding BSA release groups. Almost all the areas were mineralized in the $25 \mu \mathrm{g}$ BMP-2 release group at week 8 , while only some areas were mineralized in the $5 \mu \mathrm{g}$ BMP-2 release group. This observation was further confirmed by a calcium content assay (Fig. 5C), which demonstrated significantly higher calcium deposition in BMP-2 release groups than corresponding BSA release groups at weeks 4 and $8(p<0.05)$. Greater calcium deposition was present in the $25 \mu \mathrm{g}$ BMP-2 release group compared to the $5 \mu \mathrm{g}$ BMP-2 release group at week $8(p<0.05)$, while the difference in calcium deposition between these two groups at week 4 was not significant.

Specimens at week 8 were subjected to real-time RT-PCR and histological and immunohistochemical analyses. H\&E staining (Fig. 6A) showed that BMP-2 release groups yielded areas of mineralization with embedded cells that resemble osteodentin structure. $25 \mu \mathrm{g}$ BMP-2 release group resulted in larger amounts of osteodentin, whereas smaller amounts of osteodentin were observed in $5 \mu \mathrm{g}$ BMP-2 group. No osteodentin structure was found in corresponding BSA release groups. Masson's Trichrome staining (Fig. 6A) revealed osteodentin (dark blue stain) in BMP-2 release groups. Synthesized collagen was stained light blue in both BMP-2 and BSA release groups. DSPP protein expression in BMP-2 release groups was confirmed by immunohistochemical staining (Fig. 6A). In comparison, DSPP expression was minimal in corresponding BSA release groups. Col I, BSP, OCN, and DSPP gene expression levels were significantly up-regulated in BMP-2 release groups compared to corresponding BSA release groups ( $p<0.05$, Fig. 6B). Expression of $\mathrm{Col} \mathrm{I}$, BSP and $\mathrm{OCN}$ in the $25 \mu \mathrm{g}$ BMP-2 release group was significantly higher than the $5 \mu$ g BMP-2 release group $(p<0.05)$. 


\section{Discussion}

Advances in tissue engineering have shown the promise of novel therapies in the field of dentistry, with many examining regenerative methods for restoring the natural structure and function of the diseased dental tissues $[3,7$, 30-32]. However, their clinical relevance and applications depend on the regenerative outcome. Here, the selection of appropriate stem cell type and the design of optimal microenvironment (allowing for favorable cell-cell cell-biomaterial, and cell-signaling molecule interactions) are likely critical to the desirable outcome. Optimization of scaffold design and determination of the proper growth factors are key to maximally induce odontogenic differentiation of human SCAP for dental tissue regeneration. However, the ideal injectable scaffold structure and critical growth factor to establish optimal microenvironments to induce the odontogenic differentiation of human SCAP and dentin regeneration remain to be determined.

Various injectable scaffolds have been developed to deliver cells and to regenerate irregularly-shaped tissue defects, including injectable hydrogels, chitosan microspheres and PLGA microspheres, but none of them is ideal [5, 33, 34]. For example, injectable hydrogels have good biocompatibility, but provide insufficient cell anchorage sites and restrict cell-cell interaction upon in situ hydrogel formation $[4,5,35]$. Compared to injectable hydrogels, microspheres could provide a sufficient number of anchorage sites and better facilitate cell attachment. With the help of microspheres, cells can easily expand in 3D bioreactors such as spinner flasks [36, 37]. However, traditional solid microspheres result in large amounts of degradation byproducts and lack biomimetic surface structures to favorably interact with cells. Recently, NF-MS were developed in our group by integrating thermally-induced phase separation and emulsification techniques. The nanofibrous architecture in a porous scaffold (mimicking collagen fibers) has been demonstrated to facilitate dentin and bone tissue regeneration by promoting positive cell-material interactions, cell migration, proliferation and differentiation [32, 38-42]. The NF-MS integrate the biomimetic 
nanofibrous architecture with a injectable microsphere form. As compared to solid microspheres, NF-MS provide higher porosity and surface area for cell proliferation, extracellular matrix deposition and nutrient/waste exchange. Meanwhile, these characteristics contribute to minimizing degradation byproducts and accelerating microsphere resorption in vivo [8]. In our pilot study, SCAP cultured on SI-MS or NF-MS were induced in basic odontogenic medium (supplementary methods). The results demonstrated that the NF-MS better promoted proliferation and odontogenic differentiation of human SCAP both in vitro and in vivo (Fig. S3 - Fig. S5). Consequently, NF-MS were chosen for this study.

BMP-2 localizes in alveolar bone during root morphogenesis [43]. BMP-2 is known to be important in dentinogenesis and dentin regeneration $[3,13,14,18-21]$. When used as a capping agent, BMP-2 stimulated the formation of osteodentin and tubular dentin [14, 15, 44]. However, the effect of BMP-2 on the proliferation and odontogenic differentiation of human SCAP has not been studied until now. Because SCAP are isolated from the root apical papilla of human teeth [45], it is reasonable to hypothesize that the potent BMP-2 may induce the odontogenic differentiation of SCAP. Since BMP-2 has been approved by the Food and Drug Administration (FDA) for clinical use in accelerating spinal fusion, repairing nonunion long bone defects and inducing alveolar ridge regeneration [46], the application of BMP-2 in a dental clinical setting may likely be feasible as well. In our pilot study, BMP-2 concentration $(100 \mathrm{ng} / \mathrm{ml})$ was chosen by dosage screening. The presented data showed that 100 $\mathrm{ng} / \mathrm{ml}$ BMP-2 remarkably promoted the differentiation of human SCAP in monolayer culture but did not affect the cell proliferation significantly. This BMP-2 concentration was further found to induce the desired odontogenic differentiation and mineralization of human SCAP cultured on NF-MS in a 3D spinner flask bioreactor while maintaining a relatively high cell proliferation. ALP activity, calcium content, the expression of several odontogenic differention-associated genes (Col I, BSP, OCN and DSPP) and DSPP protein were examined. Our in vitro data 
showed that ALP activity and calcium content in BMP-2 groups were higher than those in control groups. The expression of Col I, BSP, OCN and DSPP was significantly enhanced by BMP-2 compared to the control. DSPP protein expression was strongly detected in the BMP-2 group, but was negligible in the control group. Our in vivo data further confirmed that BMP-2 promoted the dentin-like mineralized tissue formation and stronger DSPP expression compared to the control groups. All the above data clearly demonstrates that BMP-2 enhanced human SCAP ondontogenic differentiation both in monolayer culture and 3D spinner flask culture.

Although BMP-2 in soluble form promoted human SCAP ondontogenic differentiation both in vitro and in vivo, its potential application in this form is limited in clinic. Due to rapid diffusion away from the injection site and rapid loss of bioactivity in vivo [23], BMP-2 need to be injected or administrated repeatedly, resulting in complex surgery manipulation and more patient visiting times. Certain fast-setting hydrogels may retain loaded cells well. However, BMP-2 can easily diffuse out of hydrogels, leading to very short release duration (hours to 1 or 2 days). Controlled release of BMP-2 is a preferable way to address this issue. The microsphere release technology protects bioactive factors from denaturation and extends their therapeutic duration [26, 47]. Thus, in this design, BMP-2 was incorporated into PLGA MS and ELISA analysis (supplementary methods) demonstrated that bioactive BMP-2 was released from PLGA MS in a well-controlled fashion (Fig. S6). Furthermore, the in vivo results showed that BMP-2 release groups did not show significant mineralization at week 4 , but substantial mineralization was observed at week 8. This indicates that BMP-2 might function in a time-dependent manner in vivo. $25 \mu \mathrm{g}$ BMP-2 promoted a larger quantity of mineralized osteodentin tissue formation at week 8 , while $5 \mu \mathrm{g}$ BMP-2 produced a smaller amount of mineralized tissue at week 8 , indicating that BMP-2 can function in a dose-dependent manner in vivo. Moreover, the presence of red vascularized thin fibrous connective tissue in BMP-2 release groups indicated abundant angiogenesis, one of the keys to successful tissue engineering. A reasonable explanation might be that 
BMP-2 acts as a differentiation factor and chemotactic agent, inducing chemotaxis of microvascular endothelial cells and stimulating angiogenesis [48, 49]. Notably, although odontoblast-like cells and dentin-like tissue formation were observed, the tissue formed on the NF-MS did not possess the typical tubular dentin structure. Further investigation in optimizing NF-MS architecture and biological cues is needed to facilitate more natural dentin-like tissue formation.

\section{Conclusion}

Injectable NF-MS promoted odontogenic differentiation of human SCAP and dentin-like tissue formation both in vitro and in vivo, demonstrating their potential for dental tissue engineering application. The injectable NF-MS in combination with controlled release of BMP-2 showed great promise in promoting the regeneration of dentin tissues.

\section{Acknowledgements}

This study was conducted in the Polymeric Biomaterials and Tissue Engineering Laboratory at the University of Michigan with the financial support from the NIH (NIDCR DE022327 and DE015384: PXM), DOD (W81XWH-12-2-0008: PXM), and NSF (DMR-1206575: PXM). WW was partially supported by a fellowship from the Chinese Scholarship Council to conduct research at the University of Michigan under the joint advisement of PXM and LN. 


\section{Figure Captions}

Fig. 1. In vitro proliferation and odontogenic differentiation of human stem cells of apical papilla (human SCAP) in monolayer culture with BMP-2 treatment (100 ng/ml). (A) Proliferation of human SCAP at days 1, 3, 5 and 7. (B) ALP activity quantification at days 3, 7 and 14. (C) Alizarin red staining indicating mineralized nodule formation at weeks 2 and 4. (D) Quantitative analysis of the amounts of alizarin red staining at weeks 2 and 4. BMP-2 treated groups versus the control groups: $* p<0.05$.

Fig. 2. In vitro odontogenic differentiation of human SCAP cultured on nanofibrous microspheres (NF-MS) with BMP-2 treatment (100 ng/ml). (A) Schematics of 3D spinner flask culture system. (B) ALP activity quantification at days 3, 7 and 14. (C) Calcium content quantification at weeks 2 and 4. (D) Relative gene expression levels of Col I, BSP, OCN and DSPP at weeks 2 and 4. BMP-2 treated groups versus the control groups: $* p<0.05$.

Fig. 3. In vitro dentin sialophosphoprotein (DSPP) protein expression of human SCAP cultured on NF-MS with BMP-2 treatment (100 ng/ml) and without BMP-2 treatment (Control). Scale bars: $30 \mu \mathrm{m}$.

Fig. 4. Histological and immunohistochemical analyses of ectopically regenerated tissues after subcutaneous implantation for 8 weeks. The human SCAP were pre-cultured on NF-MS with BMP-2 $(100 \mathrm{ng} / \mathrm{ml})$ for 7 days. Yellow arrows indicate regenerated dentin-like tissues. Black arrows indicate positive DSPP protein staining.

Fig. 5. Mineralization of ectopic odontogenic differentiation of human SCAP cultured on NF-MS in combination 
with controlled release of BMP-2 (5 $\mu \mathrm{g}$ and $25 \mu \mathrm{g})$ at weeks 4 and 8. (A) Schematics of subcutaneous implantation procedure for the mixture of BMP-2 encapsulated microspheres (BMP-2 MS), NF-MS and human SCAP. (B) Radiographic images of regenerated tissues. (C) Calcium content quantification for regenerated tissues. ${ }^{*} p<0.05$ for BMP-2 release groups versus corresponding BSA release groups. $\# p<0.05$ for $25 \mu \mathrm{g}$ BMP-2 release group versus $5 \mu$ g BMP-2 release group at week 8 .

Fig. 6. Histological observations and gene expression profiles of ectopic odontogenic differentiation of human SCAP cultured on NF-MS in combination with controlled release of BMP-2 (5 $\mu \mathrm{g}$ and $25 \mu \mathrm{g})$ at week 8. (A) Histological and immunohistochemical analyses of regenerated tissues. (B) Relative gene expression levels of Col I, BSP, OCN and DSPP. $* p<0.05$ for BMP-2 treated groups versus corresponding BSA control groups. ${ }^{*} p<0.05$ for $25 \mu \mathrm{g}$ BMP-2 group versus $5 \mu \mathrm{g}$ BMP-2 group. 


\section{References}

[1] Zheng L, Yang F, Shen H, Hu X, Mochizuki C, Sato M, et al. The effect of composition of calcium phosphate composite scaffolds on the formation of tooth tissue from human dental pulp stem cells. Biomaterials 2011;32:7053-9.

[2] Nakashima M. Bone morphogenetic proteins in dentin regeneration for potential use in endodontic therapy. Cytokine Growth Factor Rev 2005;16:369-76.

[3] Nakashima M, Reddi AH. The application of bone morphogenetic proteins to dental tissue engineering. Nat Biotechnol 2003;21:1025-32.

[4] Fang J, Zhang Y, Yan S, Liu Z, He S, Cui L, et al. Poly(L-glutamic acid)/chitosan polyelectrolyte complex porous microspheres as cell microcarriers for cartilage regeneration. Acta Biomater 2014;10:276-88.

[5] Dreifke MB, Ebraheim NA, Jayasuriya AC. Investigation of potential injectable polymeric biomaterials for bone regeneration. J Biomed Mater Res A 2013;101:2436-47.

[6] Liu X, Jin X, Ma PX. Nanofibrous hollow microspheres self-assembled from star-shaped polymers as injectable cell carriers for knee repair. Nat Mater 2011;10:398-406.

[7] Gupte MJ, Ma PX. Nanofibrous scaffolds for dental and craniofacial applications. J Dent Res 2012;91:227-34.

[8] Ma PX. Biomimetic materials for tissue engineering. Advanced Drug Delivery Reviews 2008;60:184-98.

[9] Lovelace TW, Henry MA, Hargreaves KM, Diogenes A. Evaluation of the delivery of mesenchymal stem cells into the root canal space of necrotic immature teeth after clinical regenerative endodontic procedure. J Endod 2011;37:133-8.

[10] Huang GT, Yamaza T, Shea LD, Djouad F, Kuhn NZ, Tuan RS, et al. Stem/progenitor cell-mediated de novo regeneration of dental pulp with newly deposited continuous layer of dentin in an in vivo model. Tissue Eng Part A 2010;16:605-15.

[11] Huang GT, Gronthos S, Shi S. Mesenchymal stem cells derived from dental tissues vs. those from other sources: their biology and role in regenerative medicine. J Dent Res 2009;88:792-806.

[12] Kirker-Head CA. Potential applications and delivery strategies for bone morphogenetic proteins. Adv Drug Deliv Rev 2000;43:65-92.

[13] Saito T, Ogawa M, Hata Y, Bessho K. Acceleration effect of human recombinant bone morphogenetic protein-2 on differentiation of human pulp cells into odontoblasts. J Endod 2004;30:205-8.

[14] Iohara K, Nakashima M, Ito M, Ishikawa M, Nakasima A, Akamine A. Dentin regeneration by dental pulp stem cell therapy with recombinant human bone morphogenetic protein 2. J Dent Res 2004;83:590-5.

[15] Nakashima M. Induction of dentin formation on canine amputated pulp by recombinant human bone morphogenetic proteins (BMP)-2 and -4. J Dent Res 1994;73:1515-22. 
[16] Nakashima M. Induction of dentine in amputated pulp of dogs by recombinant human bone morphogenetic proteins-2 and -4 with collagen matrix. Arch Oral Biol 1994;39:1085-9.

[17] Goldberg M, Six N, Decup F, Buch D, Soheili Majd E, Lasfargues JJ, et al. Application of bioactive molecules in pulp-capping situations. Adv Dent Res 2001;15:91-5.

[18] Nakashima M, Nagasawa H, Yamada Y, Reddi AH. Regulatory role of transforming growth factor-beta, bone morphogenetic protein-2, and protein-4 on gene expression of extracellular matrix proteins and differentiation of dental pulp cells. Dev Biol 1994;162:18-28.

[19] Zhao M, Xiao G, Berry JE, Franceschi RT, Reddi A, Somerman MJ. Bone morphogenetic protein 2 induces dental follicle cells to differentiate toward a cementoblast/osteoblast phenotype. J Bone Miner Res 2002;17:1441-51.

[20] Casagrande L, Demarco FF, Zhang Z, Araujo FB, Shi S, Nor JE. Dentin-derived BMP-2 and odontoblast differentiation. J Dent Res 2010;89:603-8.

[21] Tasli PN, Aydin S, Yalvac ME, Sahin F. Bmp 2 and bmp 7 induce odonto- and osteogenesis of human tooth germ stem cells. Appl Biochem Biotechnol 2014;172:3016-25.

[22] Wozney JM, Rosen V. Bone morphogenetic protein and bone morphogenetic protein gene family in bone formation and repair. Clin Orthop Relat Res 1998:26-37.

[23] Boerckel JD, Kolambkar YM, Dupont KM, Uhrig BA, Phelps EA, Stevens HY, et al. Effects of protein dose and delivery system on BMP-mediated bone regeneration. Biomaterials 2011;32:5241-51.

[24] Babensee JE, Mclntire LV, Mikos AG. Growth factor delivery for tissue engineering. Pharm Res 2000;17:497-504.

[25] Wei G, Pettway GJ, McCauley LK, Ma PX. The release profiles and bioactivity of parathyroid hormone from poly(lactic-co-glycolic acid) microspheres. Biomaterials 2004;25:345-52.

[26] Wei G, Jin Q, Giannobile WV, Ma PX. The enhancement of osteogenesis by nano-fibrous scaffolds incorporating rhBMP-7 nanospheres. Biomaterials 2007;28:2087-96.

[27] Jin Q, Wei G, Lin Z, Sugai JV, Lynch SE, Ma PX, et al. Nanofibrous scaffolds incorporating PDGF-BB microspheres induce chemokine expression and tissue neogenesis in vivo. PLoS One 2008;3:e1729.

[28] Sonoyama W, Liu Y, Yamaza T, Tuan RS, Wang S, Shi S, et al. Characterization of the apical papilla and its residing stem cells from human immature permanent teeth: a pilot study. J Endod 2008;34:166-71.

[29] Sonoyama W, Liu Y, Fang D, Yamaza T, Seo BM, Zhang C, et al. Mesenchymal stem cell-mediated functional tooth regeneration in swine. PLoS One 2006;1:e79.

[30] Wang J, Liu X, Jin X, Ma H, Hu J, Ni L, et al. The odontogenic differentiation of human dental pulp stem cells on nanofibrous poly(L-lactic acid) scaffolds in vitro and in vivo. Acta Biomater 2010;6:3856-63.

[31] Huang GT. Pulp and dentin tissue engineering and regeneration: current progress. Regen Med 2009;4:697-707.

[32] Wang J, Ma H, Jin X, Hu J, Liu X, Ni L, et al. The effect of scaffold architecture on odontogenic differentiation of 
human dental pulp stem cells. Biomaterials 2011;32:7822-30.

[33] Jayasuriya AC, Bhat A. Fabrication and characterization of novel hybrid organic/inorganic microparticles to apply in bone regeneration. J Biomed Mater Res A 2010;93:1280-8.

[34] Francisco AT, Mancino RJ, Bowles RD, Brunger JM, Tainter DM, Chen YT, et al. Injectable laminin-functionalized hydrogel for nucleus pulposus regeneration. Biomaterials 2013;34:7381-8.

[35] Kloxin AM, Kasko AM, Salinas CN, Anseth KS. Photodegradable hydrogels for dynamic tuning of physical and chemical properties. Science 2009;324:59-63.

[36] Martin Y, Eldardiri M, Lawrence-Watt DJ, Sharpe JR. Microcarriers and their potential in tissue regeneration. Tissue Eng Part B Rev 2011;17:71-80.

[37] Malda J, Frondoza CG. Microcarriers in the engineering of cartilage and bone. Trends Biotechnol 2006;24:299-304.

[38] Smith LA, Liu X, Hu J, Ma PX. The influence of three-dimensional nanofibrous scaffolds on the osteogenic differentiation of embryonic stem cells. Biomaterials 2009;30:2516-22.

[39] Woo KM, Chen VJ, Jung HM, Kim TI, Shin HI, Baek JH, et al. Comparative evaluation of nanofibrous scaffolding for bone regeneration in critical-size calvarial defects. Tissue Eng Part A 2009;15:2155-62.

[40] Woo KM, Chen VJ, Ma PX. Nano-fibrous scaffolding architecture selectively enhances protein adsorption contributing to cell attachment. J Biomed Mater Res A 2003;67:531-7.

[41] Woo KM, Jun JH, Chen VJ, Seo J, Baek JH, Ryoo HM, et al. Nano-fibrous scaffolding promotes osteoblast differentiation and biomineralization. Biomaterials 2007;28:335-43.

[42] Smith LA, Liu X, Hu J, Wang P, Ma PX. Enhancing osteogenic differentiation of mouse embryonic stem cells by nanofibers. Tissue Eng Part A 2009;15:1855-64.

[43] Thomadakis G, Ramoshebi LN, Crooks J, Rueger DC, Ripamonti U. Immunolocalization of Bone Morphogenetic Protein-2 and -3 and Osteogenic Protein-1 during murine tooth root morphogenesis and in other craniofacial structures. Eur J Oral Sci 1999;107:368-77.

[44] Lianjia Y, Yuhao G, White FH. Bovine bone morphogenetic protein-induced dentinogenesis. Clin Orthop Relat Res 1993:305-12.

[45] Friedlander LT, Cullinan MP, Love RM. Dental stem cells and their potential role in apexogenesis and apexification. Int Endod J 2009;42:955-62.

[46] McKay WF, Peckham SM, Badura JM. A comprehensive clinical review of recombinant human bone morphogenetic protein-2 (INFUSE Bone Graft). Int Orthop 2007;31:729-34.

[47] Wei G, Jin Q, Giannobile WV, Ma PX. Nano-fibrous scaffold for controlled delivery of recombinant human PDGF-BB. J Control Release 2006;112:103-10.

[48] Li G, Cui Y, Mcllmurray L, Allen WE, Wang H. rhBMP-2, rhVEGF(165), rhPTN and thrombin-related peptide, TP508 induce chemotaxis of human osteoblasts and microvascular endothelial cells. J Orthop Res 2005;23:680-5. 
[49] Rao SM, Ugale GM, Warad SB. Bone morphogenetic proteins: periodontal regeneration. N Am J Med Sci 2013;5:161-8. 
A

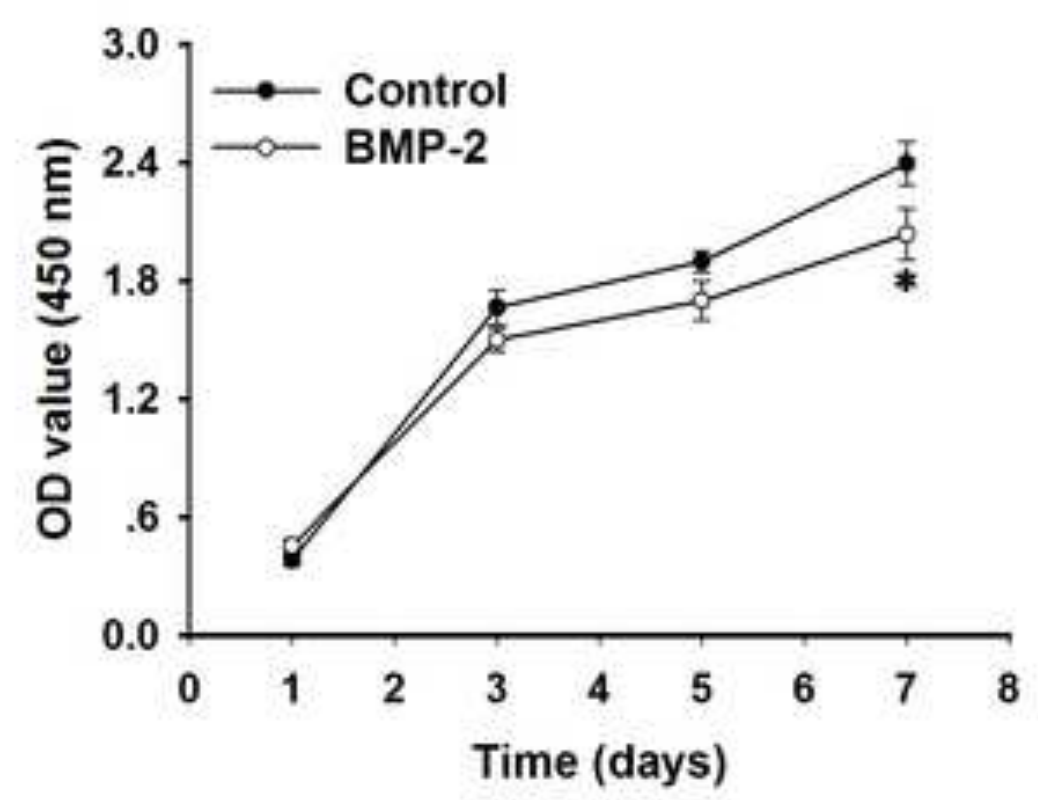

C

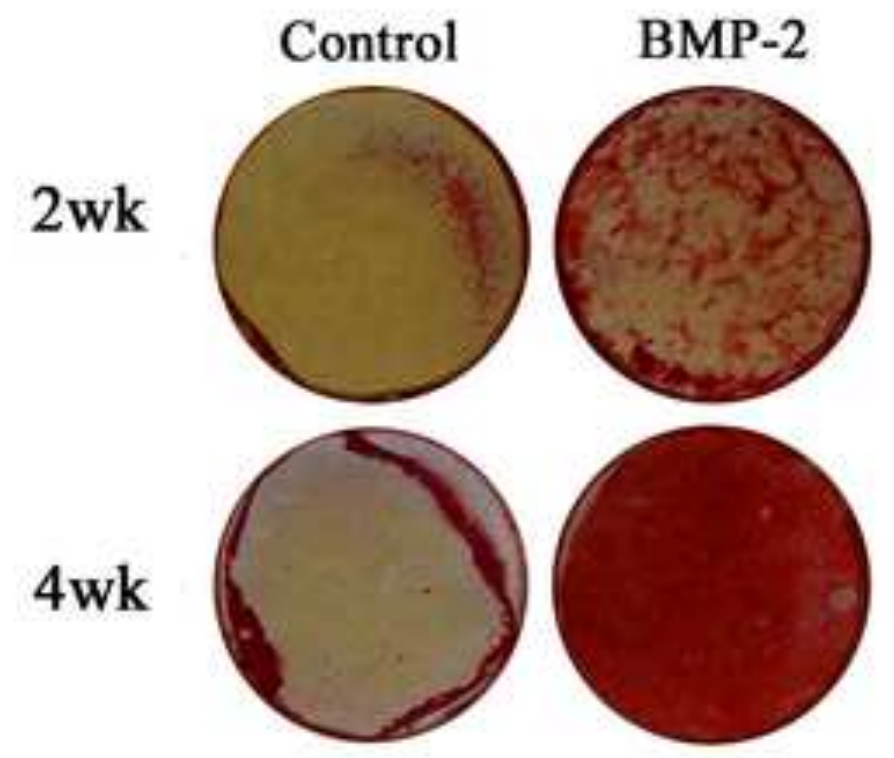

B

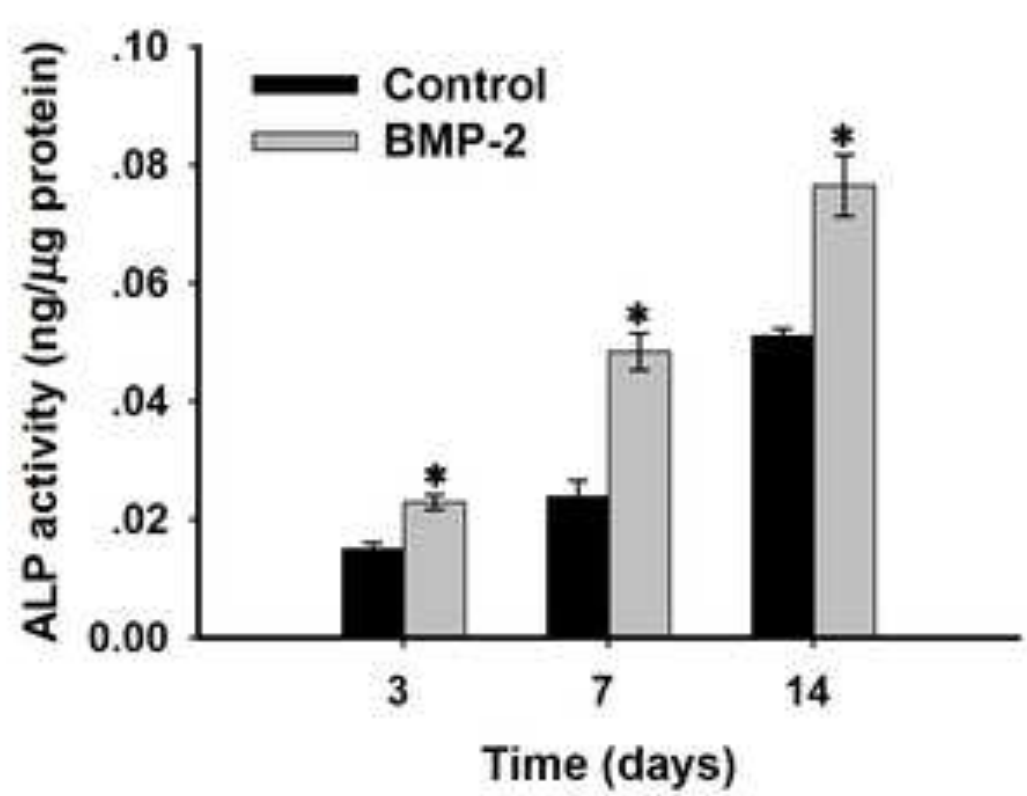

D

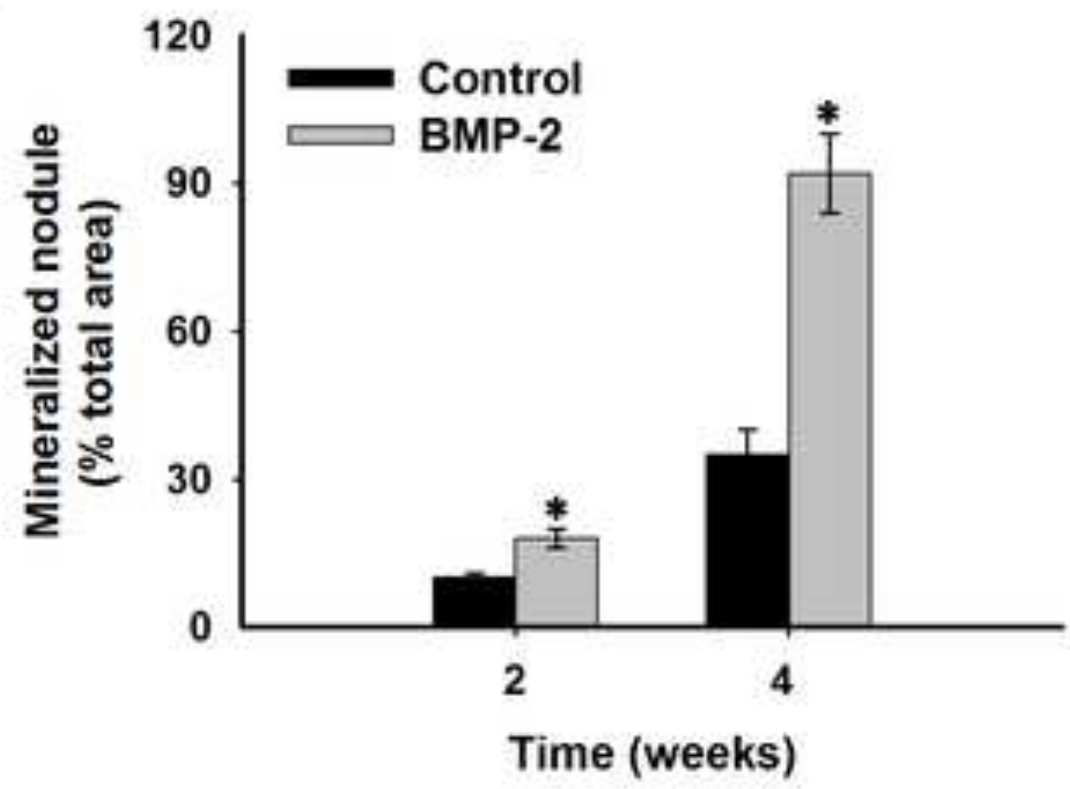


A

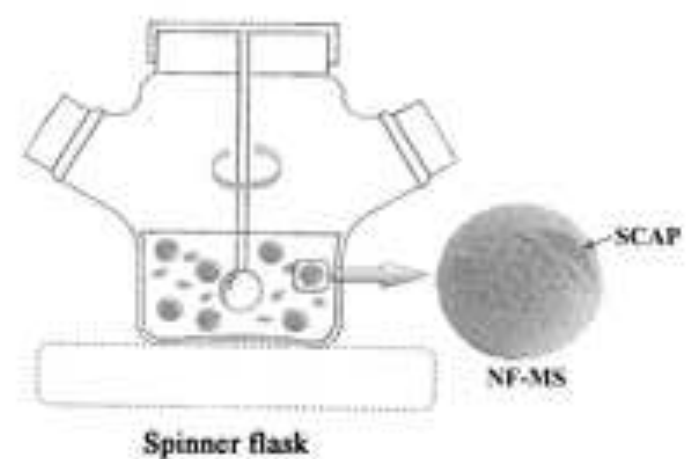

B

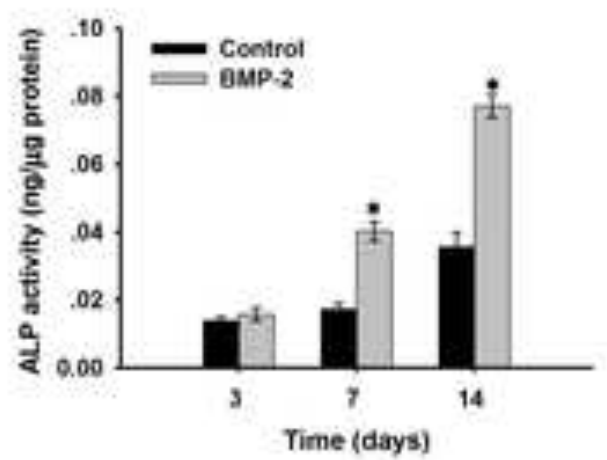

C

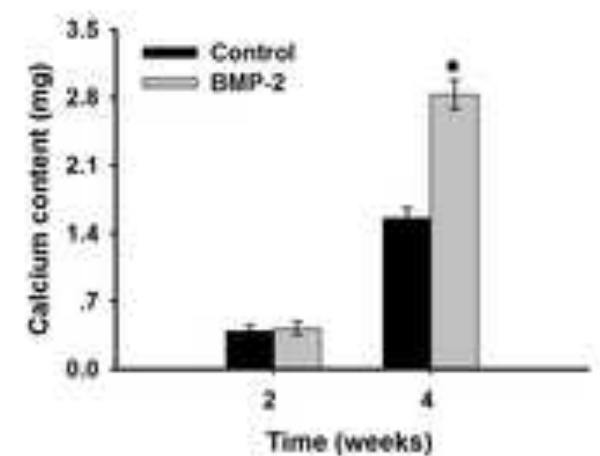

D

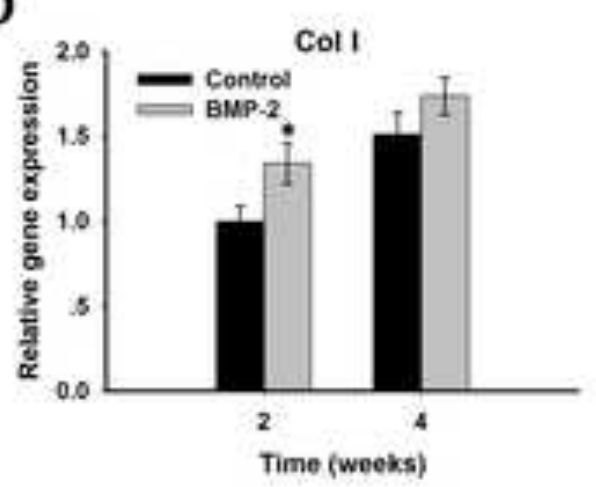

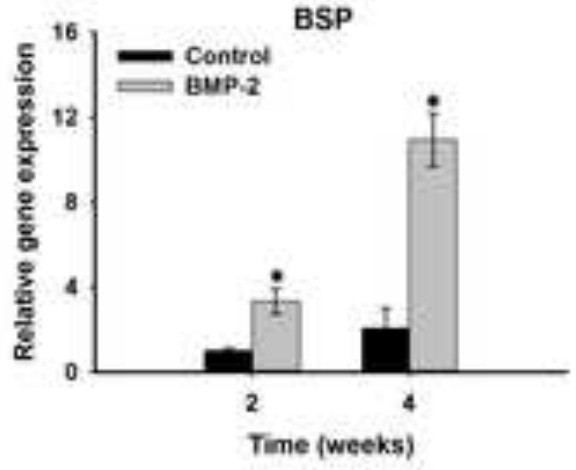

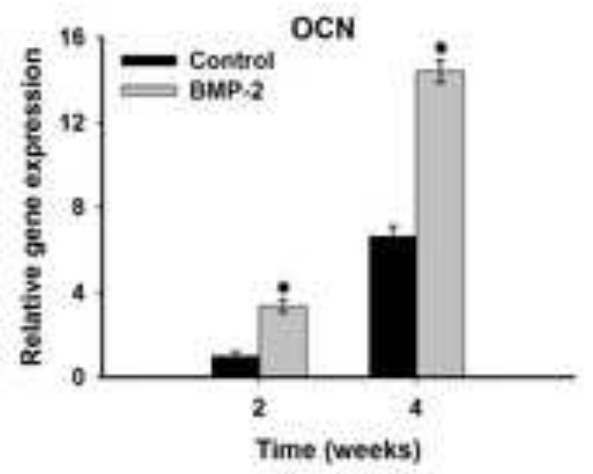

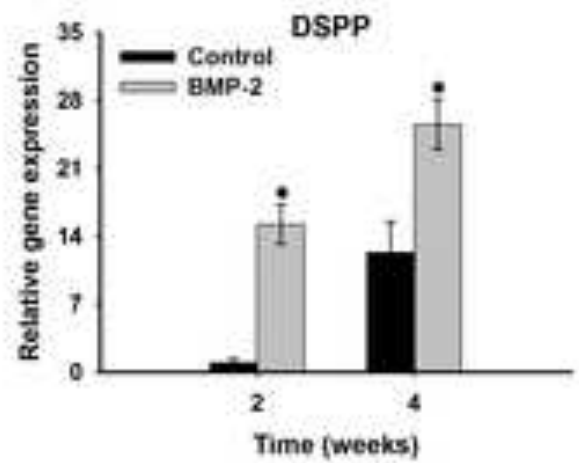



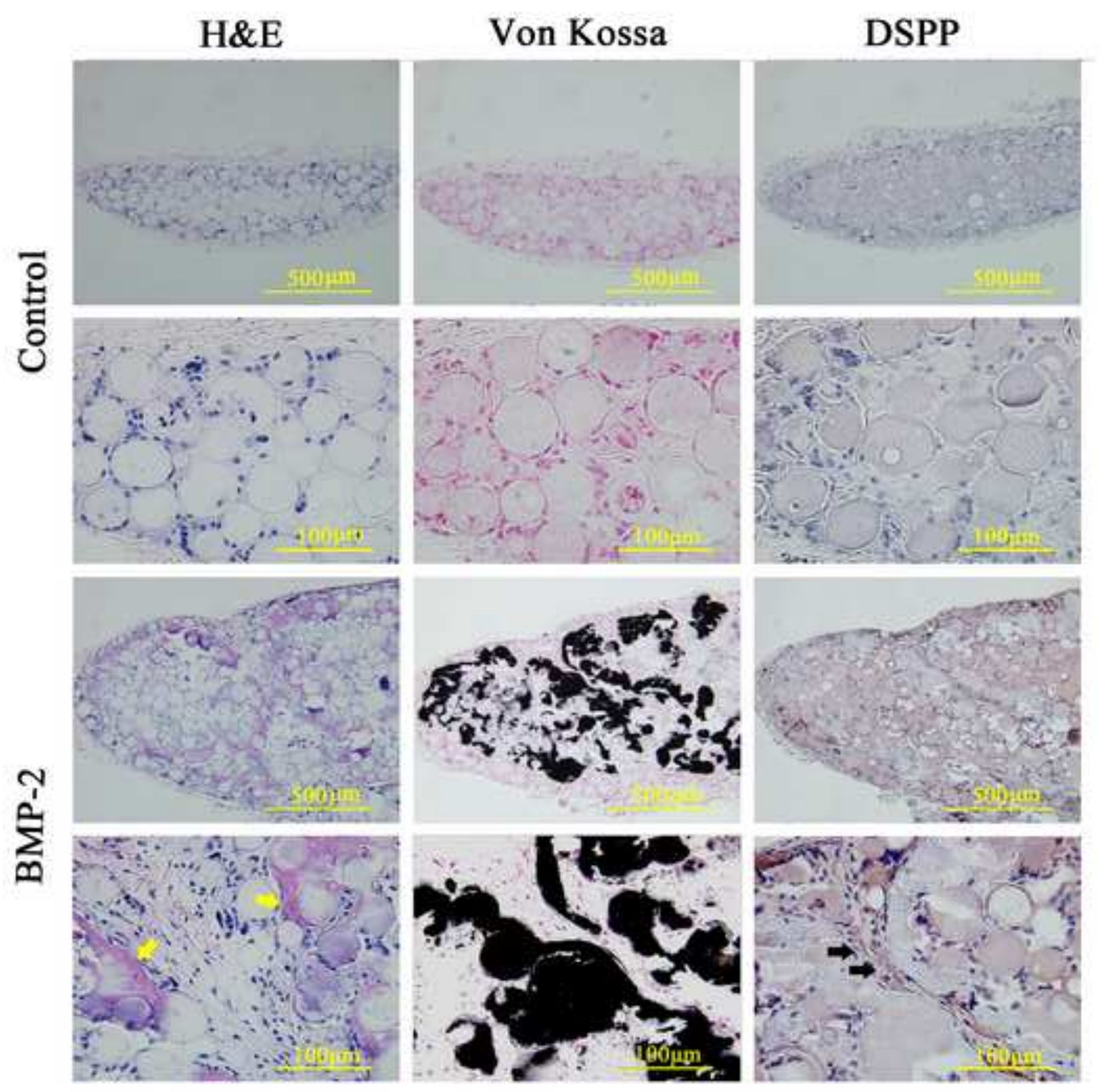
A

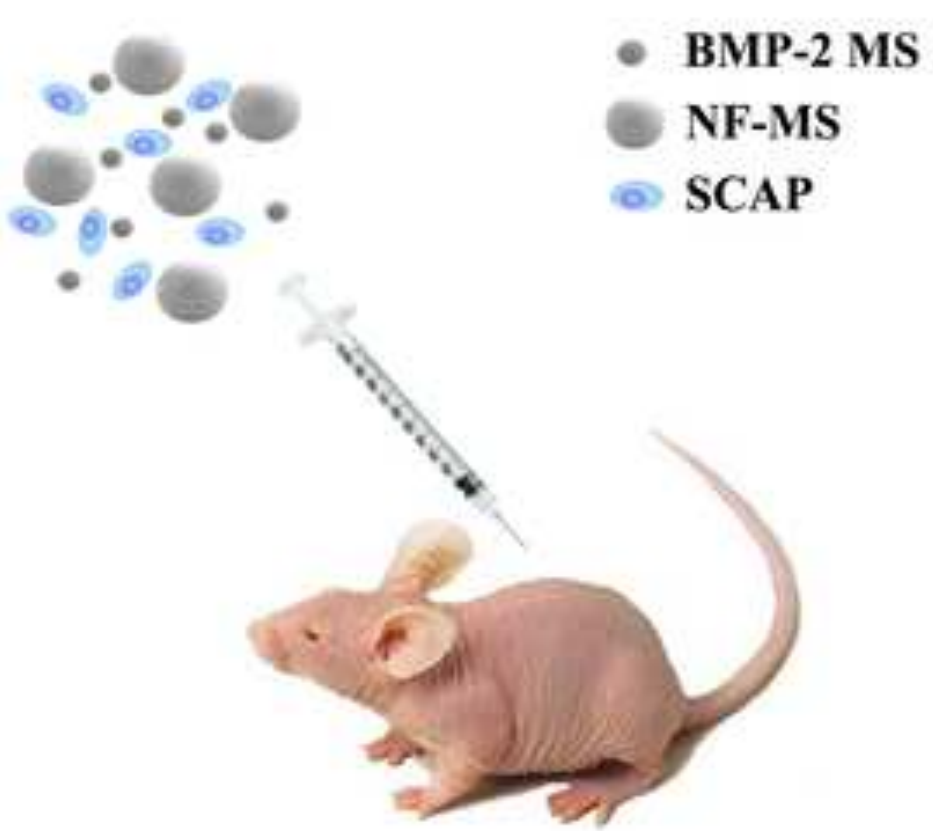

C

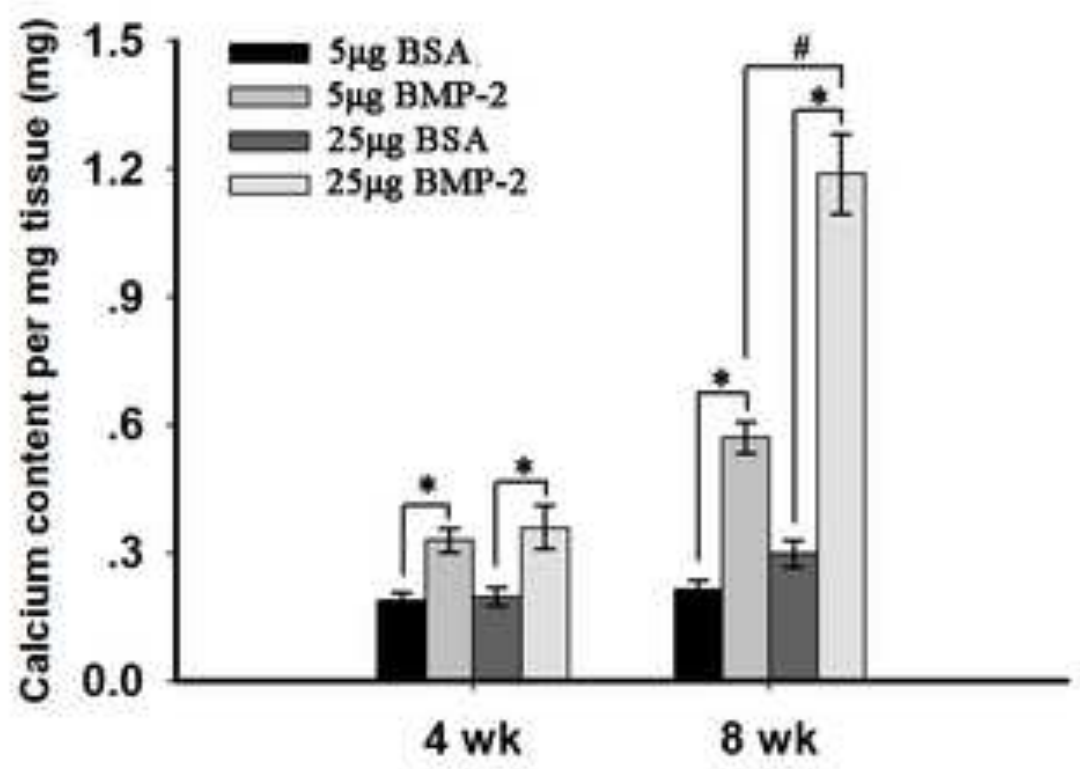

B

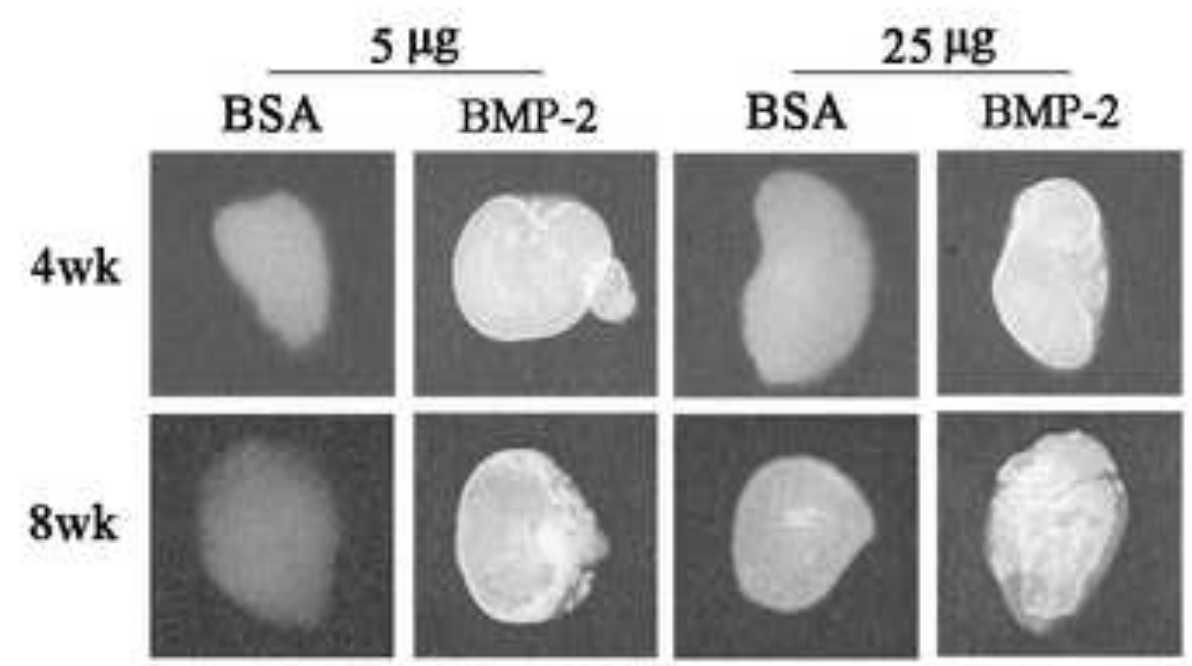


Figure-6

A

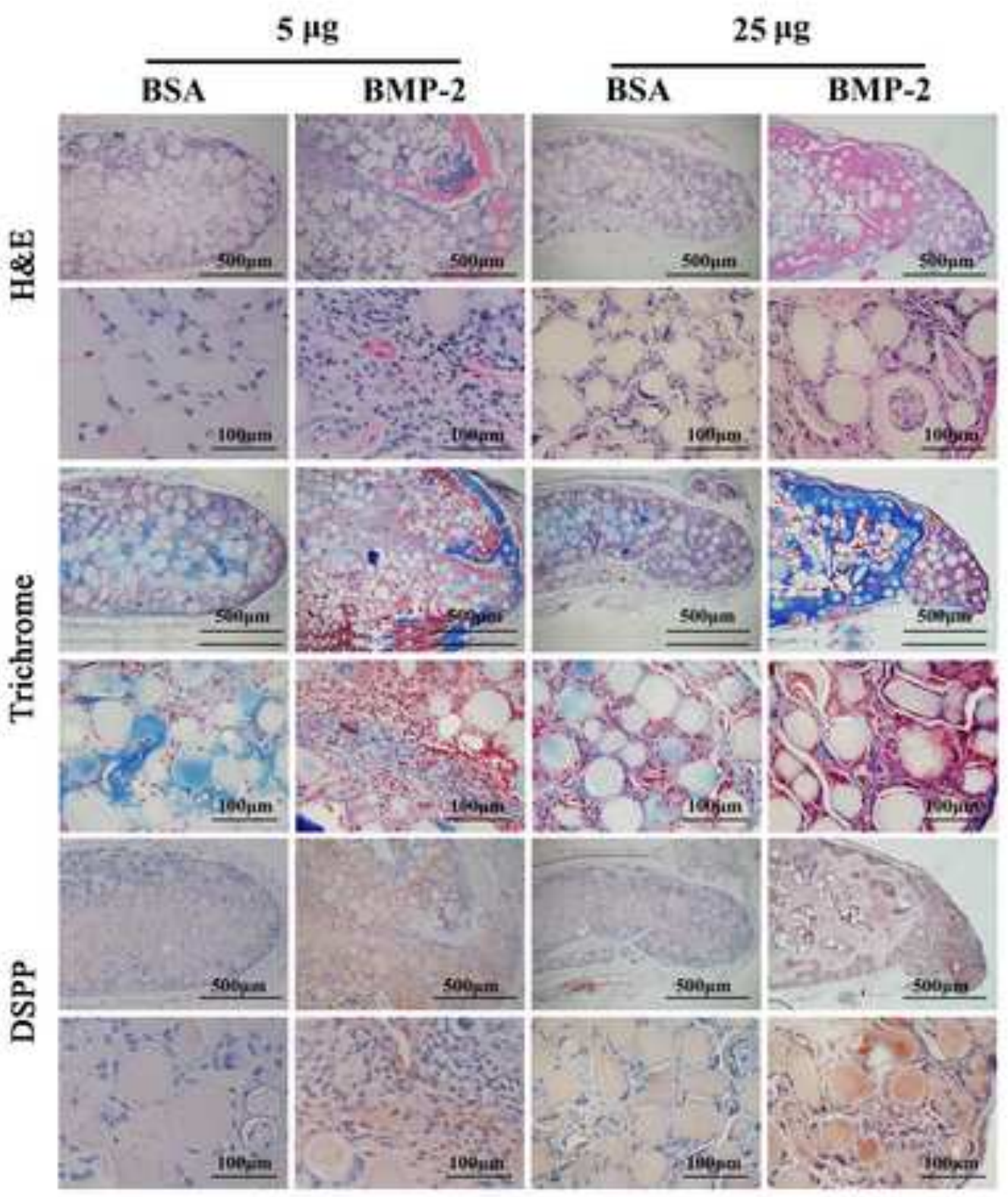

B

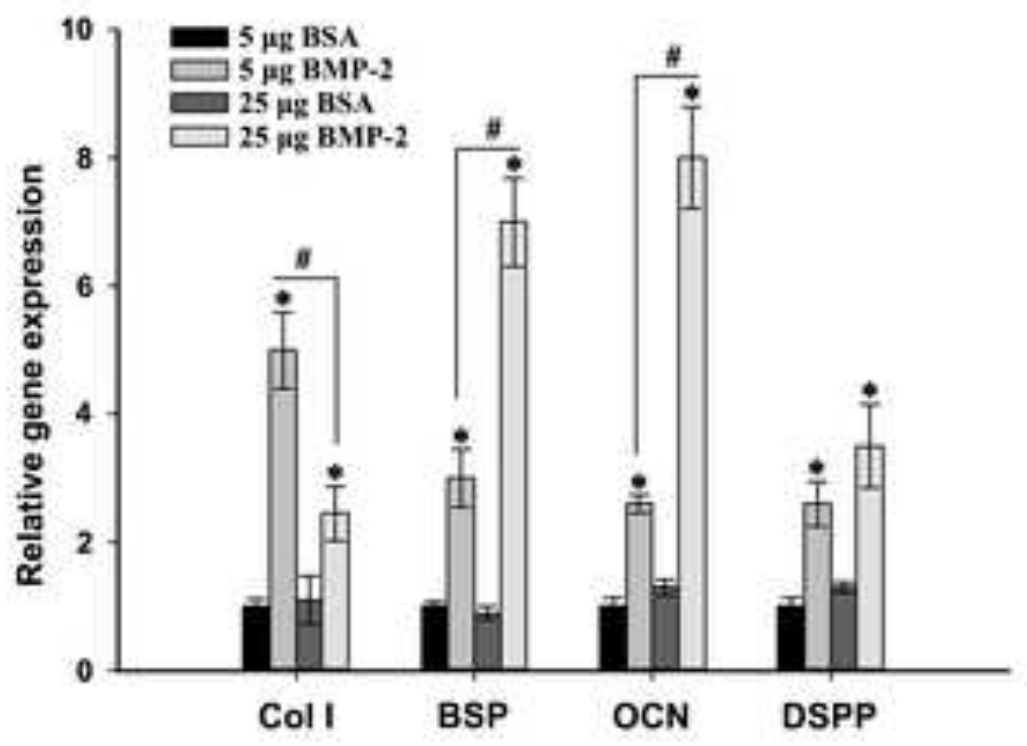




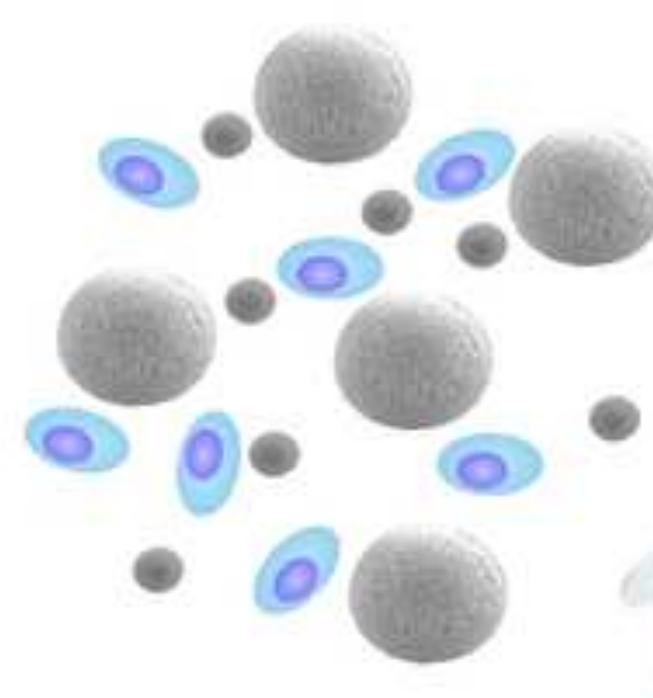

- BMP-2 MS NF-MS

(2) SCAP

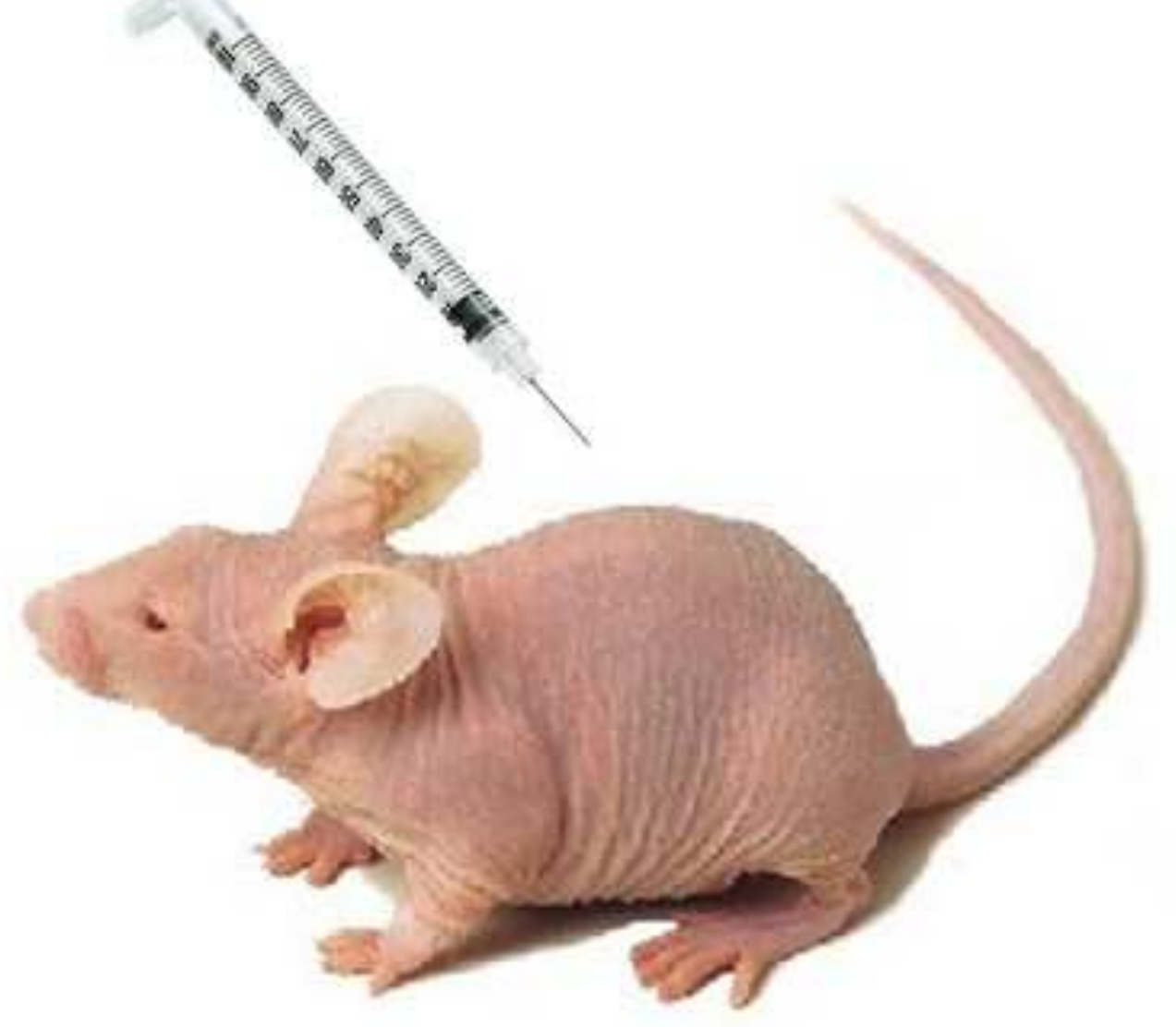

